\title{
Application of Plant Metabonomics in Quality Assessment for Large-Scale Production of Traditional Chinese Medicine
}

Authors

Affiliations
Zhangchi Ning ${ }^{1}$, Cheng Lu², Yuxin Zhang ${ }^{1}$, Siyu Zhao ${ }^{1}$, Baoqin Liu ${ }^{3}$, Xuegong Xu ${ }^{3}$, Yuanyan Liu

${ }^{1}$ School of Chinese Materia Medica, Beijing University of Chinese Medicine, Beijing, China

2 Institute of Basic Research in Clinical Medicine, China Academy of Chinese Medical Sciences, Beijing, China

${ }^{3}$ Zhengzhou Hospital of Traditional Chinese Medicine, Zhengzhou, China
Key words

- plant metabonomics

- large-cale production

- discrimination

- processing

pharmaceutics

\section{Abstract}

$\nabla$

The curative effects of traditional Chinese medicines are principally based on the synergic effect of their multi-targeting, multi-ingredient preparations, in contrast to modern pharmacology and drug development that often focus on a single chemical entity. Therefore, the method employing a few markers or pharmacologically active constituents to assess the quality and authenticity of the complex preparations has a number of severe challenges. Metabonomics can provide an effective platform for complex sample analysis. It is also reported to be applied to the quality analysis of the traditional Chinese medicine. Metabonomics enables comprehensive assessment of complex traditional Chinese medicines or herbal remedies and sample classification of diverse biological statuses, origins, or qualities in samples, by means of chemometrics. Identification, processing, and pharmaceutical preparation are the main procedures in the large-scale production of Chinese medicinal preparations. Through complete scans, plants metabonomics addresses some of the shortfalls of single analyses and presents a considerable potential to become a sharp tool for traditional Chinese medicine quality assessment.

Abbreviations
$\nabla$
TCM:
CE:
MVDA:
PCA:

Correspondence

Institute of Basic Research in

Clinical Medicine

China Academy of Chinese

Medical Sciences

Nonxiaojie $16^{\#}$ Dong zhimen

Beijing 100700

China

Phone: +8610640144113403

Fax: +861084032881

Iv_cheng0816@163.com

HCA:

PLS:

OSC:

OPLS:

traditional Chinese medicine capillary electrophoresis multivariate data analysis principal component analysis hierarchical cluster analysis partial least squares orthogonal signal correction orthogonal partial least squares
O2PLS:

PLS-DA:

kNN:

ANN:

MEND:

AFLP:

TOF:

UPLC-QTOF-MS: $\quad$ ultra performance liquid

BP-ANN:

ELSD:

HPTLC:

DART:

PAD:

LS-SVM:

RBF:

NIRS:

WG:

RG:

LTQ:

LDA:

SA: chromatography quadrupole time of flight high definition mass spectrometry back propagation artificial neural network

bidirectional orthogonal partial least squares soft independent modeling of class analogy partial least squares discriminant analysis $\mathrm{k}$ nearest neighbors artificial neural networks matched filtration with experimental noise determination amplified fragment length polymorphism evaporative light scattering detector

high performance thin layer chromatography direct analysis in real time photodiode array detector least squares support vector machine

radial basis function near-infrared spectroscopy white ginseng red ginseng linear discriminant analysis similarity analysis correlation optimized warping unweighted pair group method with arithmetic mean linear trap quadrupole 
FSMWEFA:

fixed size moving window-evolving factor analysis

HELP:

heuristic evolving latent

projection

LA:

RRLC:

UFLC:

licochalcone $\mathrm{A}$

MAS-NMR:

rapid resolution liquid chromatography

ultrafast liquid chromatography

magic angle spinning nuclear magnetic

resonance

IOP:

SFA:

OPR:

EWOP:

5-GGMF: iterative optimization procedure

subwindow factor analysis

orthogonal projection resolution

evolving window orthogonal projection

5-( $\alpha$-D-glucopyranosyl-(1-6)- $\alpha$-D-glucopy-

ranosyloxymethyl)-2-furancarboxaldehyde
NMR:

MS:

TOF:

UPLC-QTOFMS: $\quad$ ultra-performance liquid chromatographyquadrupole time-of-flight mass spectrometry

UPLC-QTOF-HDMS: ultra-performance liquid chromatographyquadrupole time-of-flight high-definition mass spectrometry

UPLC-PAD: $\quad$ ultra-performance liquid chromatography with photodiode array detector

LC-LTQ-Orbitrap: $\quad$ LC coupled with ESI hybrid linear trap quadrupole orbitrap

\section{Introduction}

$\nabla$

Metabonomics is an emerging subject of the post-genome era, which, together with genomics, transcriptomics, and proteomics, jointly constitutes the "Systems Biology" [1]. It is the branch of science concerned with the quantitative understanding of the metabolite components of integrated living systems and their dynamic responses to changes in both endogenous (such as those associated with physiology and development) and exogenous factors (such as environmental factors and xenobiotics) [2]. The success of the application of metabonomics has been illustrated in the literature from the perspective of the diagnosis of diseases such as diabetes [3], hypertension [4], and cancers [5,6]. In recent years, a wide range of analytical metabonomic techniques have been implemented in research addressing TCM whose qualitative analysis is difficult because of the complexity and diversity of its components. In general, one or two biomarkers are used for identification and authentication of the herbal products. However, this approach does not provide information on the overall chemical composition of the plant extract, which is known to vary widely according to geographical origin, source, cultivar condition, harvesting and processing methods, and storage. Metabonomics, through achieving complete scans, addresses the shortfalls of single-component analysis. The rapid development of analytical instruments is accelerating research on TCM [7]. Additionally, multivariate statistical methods are increasingly improving, allowing the implementation of robust solutions [8].

Within the TCM practice, the majority of species used are plants. The multi-varieties employed in TCM are the main cause of confusion in the herbal medicine market. The identification of these varieties, as the first step in the production of Chinese medicinal preparations, is of great significance for ensuring the safety and effectiveness of clinical treatment. The quality and contents of the active components of herbs are highly variable depending on the species, parts of the herbs, cultivated geographic region, and planting period involved. Adulterants should be distinguishable from plant material and play the role of challenging substances. The processing of a characteristic portion, as the second step in production, appears to be of significance in clinical applications and has been proven to satisfy the requirements of therapeutics. It is essential to unify the degree of processing. In pharmaceutical production, extracts are commonly used. Metabonomics can be effectively applied for the quality control of plant extracts.
Identifying the plant material, processing, and pharmaceutical production is the sequence of manufacture for Chinese medicinal preparations. Here we demonstrate the application of metabonomics in the discrimination of TCM species, TCM production processes, and quality control. To avoid ambiguities, we also illustrated the factors affecting the identification step, the methods used in processing, and the forms of the pharmaceuticals.

\section{Analytical Techniques \\ $\nabla$}

In recent years, many metabonomic-based methods have been implemented to facilitate research in the field of TCM. In the pharmacopeia, single-component analyses are employed in most research addressing TCM. Nevertheless, the lack of representativeness of single-component analyses seems to account for a deficiency of convincing data. Metabonomics, through achieving complete scans, addresses the shortfalls of single-component analysis.

The rapid development of analytical instruments is accelerating research on TCM [7]. Metabonomics measures the multi-parametric response of biological systems to a stimulus, typically employing analytical technologies such as NMR or MS to obtain comprehensive profiling and comparison of metabolic "fingerprints" [9]. In addition, other chemical analytical equipments and techniques, such as UV and IR spectroscopy were also employed. For biomarker identification, it is also possible to separate out substances of interest on a larger scale from a complex biological system using techniques such as LC, multidimensional liquid separation systems, GC, and CE. Especially multidimensional liquid separation systems have the potential to become a powerful approach for enriching, separating, and quantifying a large variety of exogenous and endogenous compounds in complex biological samples and TCM preparations, with a powerful separation ability, high resolution and sensitivity, high-peak capacity, and excellent detection in comparison with one-dimensional HPLC. However, every analytical technique has its advantages and drawbacks, as shown in Table 1. Multi-analysis techniques can partially overcome the shortcomings of individual analytical techniques. It is believed that with the further development of metabonomics analysis techniques, especially those employing multi-analysis, metabonomics will strongly promote TCM research and be beneficial to its modernization in terms of extending the application of modern methods in the assessment of TCM 
Table 1 Comparison of analytical techniques.

\begin{tabular}{|c|c|}
\hline & Advantages and problems \\
\hline $\begin{array}{l}\text { LC } \\
{[7,96-99]}\end{array}$ & $\begin{array}{l}\text { - Low cost } \\
\text { - Easy to use } \\
\text { - Highly sensitive } \\
\text { - Not limited by sample volatility and stability } \\
\text { - Favorable separating power }\end{array}$ \\
\hline $\begin{array}{l}\text { NMR } \\
{[100]}\end{array}$ & $\begin{array}{l}\text { - Noninvasive and nondestructive for samples } \\
\text { - Quantitative and simultaneous detection unbiased for } \\
\text { any molecules } \\
\text { - High throughput } \\
\text { - Produces rich, dynamic molecular information } \\
\text { - Requires little or no sample preparation } \\
\text { - Good resolution and reproducibility }\end{array}$ \\
\hline $\begin{array}{l}\text { GC } \\
{[7,101]}\end{array}$ & $\begin{array}{l}\text { High sensitive detection for almost both volatile } \\
\text { chemical and nonvolatile compounds } \\
\text { Has more peak capacity and can accommodate more } \\
\text { complex mixtures } \\
\text { Unsuitable for nonvolatile and thermally unstable } \\
\text { compounds }\end{array}$ \\
\hline $\begin{array}{l}\text { CE and HPCE } \\
{[7,102]}\end{array}$ & $\begin{array}{l}\text { - High speed and short analysis time } \\
\text { - Less sample and solvent consumption } \\
\text { - Appropriate for complex samples } \\
\text { - Lower operating cost } \\
\text { - Lower sensitivity than HPLC }\end{array}$ \\
\hline $\begin{array}{l}\text { MS } \\
{[15,103,104]}\end{array}$ & $\begin{array}{l}\text { - Realize identification and quantification of volatile and } \\
\text { thermally stable components } \\
\text { - Used for ionization of polar to nonpolar components } \\
\text { - Associates with LC overcoming problems } \\
\text { - Being destructive } \\
\text { - Requiring preknowledge about samples } \\
\text { - High recurrent expenditures }\end{array}$ \\
\hline $\begin{array}{l}\text { UV } \\
\text { [105] }\end{array}$ & $\begin{array}{l}\text { - Easy to be applied } \\
\text { - Limited use for compounds without UV absorption } \\
\text { - Lacks specificity }\end{array}$ \\
\hline $\begin{array}{l}\text { IR } \\
\text { [106-108] }\end{array}$ & $\begin{array}{l}\text { Potential to use vibrational spectroscopy } \\
\text { - Lacks specificity } \\
\text { - Signal overlapping }\end{array}$ \\
\hline
\end{tabular}

safety, assisting in the formulation of TCM safety norms, and establishing international standards [7].

\section{Data Processing Methods \\ $\nabla$}

The progress of metabonomics research will be illustrated. First, the proposed TCM component should be extracted. Second, analytical tools should be applied. Third, the chemical profile should be obtained. Combining data under a multivariate data analysis, validating models, molding, and applying diagnostic tools are the consecutive steps [10] supported by chemometrics and mathematical statistics.

Chemometrics are basically classified into two main categories: pattern recognition methods (unsupervised and supervised), when a qualitative evaluation is involved, and multivariate calibration for quantitative purposes. Data resulting from metabonomics-based work are typically high-dimensional data, requiring MVDA methods for interpretation. Most metabonomics data analysis methods are based on the classification of samples into different groups (e.g., by treatment or genotype), both via supervised (e.g., discriminant function analysis or artificial neural networks) and unsupervised data analysis methods (e.g., PCA or HCA) [11]. It is also possible to use MVDA to conduct regression modeling between two blocks of data, usually denoted as $\mathrm{X}$ and Y. In metabonomics-based NP studies, $\mathrm{X}$ may represent signals from different metabolites present in plant extracts sampled at regular time intervals, while $\mathrm{Y}$ represents responses (e.g., the quality of product, bioactivity, or yield). The model then can be used to predict $Y$ from $X$, which is achieved through new observations. The most common MVDA method employed for this type of modeling is the PLS method [12]. Recently, OSC, OPLS, and O2PLS were utilized $[13,14]$. The specific methods include SIMCA, PLS-DA, kNN, and ANN. Moreover, PCA and HCA are widely used in metabonomics research.

Model validation consists of cross validation, permutation testing, and external validation [10]. There are two significant procedures: noise filtration and peak matching [15]. Nonlinear noise filtration is extensively employed, substituting a point with the average of the surrounding points so as to filter noise successfully [16]. Matched filtration is another method setting up a standard mode of a peak and comparing its width; a narrower peak is regarded as noise [17]. Andreev et al. [18] developed MEND, improving the identification function. As for peak matching, identifying the retention time of the internal standard substance under the same conditions is the main method employed.

The main diagnostic tools applied include score plots, loading plots, VIP, DModX, and regression coefficients [10]. MetExtract, a new software tool for the automated comprehensive extraction of metabolite-derived LC/MS signals in metabonomics research, was recently reported in the literature [19].

\section{Bioactivity and Profiles}

\section{$\nabla$}

The main research methods of metabonomics are metabolomic fingerprinting and metabolomic profiling analysis. Metabolomic profiling can be divided into two parts, targeted and nontargeted metabolic profiling analysis.

The targeted metabolic profiling aims to search one biomarker. Several components were usually chosen as marker compounds to assess the quality. These biomarkers were proved to be constituents that discriminate the different species, different parts, different cultivated geographic regions, different planting periods, and the processing products. In the present paper, the bioactivities of the biomarkers were obtained via PubChem (http:// www.ncbi.nlm.nih.gov/pccompound) and related literatures.

However, these few selected markers sometimes are not unique to a particular herb since they might be present in many plants belonging to various families. In addition, the selection of suitable markers is sometimes difficult and subjective. Furthermore, adulterators are continuously trying to develop ways to make their products' chemical profile similar to the authentic medicinal herbal product. Under these specific circumstances, the marker approach, on the one hand, is unable to confirm the identity of a specific plant. On the other hand, the influences of the other inner chemicals present may be ignored. Therefore, in some cases, its use may be inappropriate for quality control purposes $[20,21]$. The objective of "nontargeted" analysis is to describe metabolic events by determining all detectable metabolites [22]. Of the various profiling techniques, nontargeted analysis using UPLC-MS is a promising tool for investigating the diversity of phytochemicals [23]. Thus, it is believed that nontargeted metabolic profiling analysis will play an important role as an effective tool in terms of high-throughput elucidation of metabolic phenotypes. 


\section{Identification of Traditional Chinese Medicine Components \\ $\nabla$}

The identification of traditional Chinese medicine components plays a key role in ensuring the safety and effectiveness of clinical treatments. The quality and contents of the active constituents in herbs are highly variable depending on the species, parts of the plant, cultivated geographic region, and planting period involved. Adulterants are assumed to be distinguishable from plant material and play the role of challenging substances. Therefore, during large-scale production, the identification of these components is of vital significance. Moreover, many applications employed in the development of metabolic fingerprinting, which will be explained below, using appropriate analysis methods coupled with multivariate analysis, have been investigated and applied to discriminate between closely related plant species in performing quality control assessments of herbal drugs and to identify their different geographic origins. In addition, analyzing components is a robust way to control plant quality.

Here, the identification of TCM components can be divided into four categories: the various species and adulterants, the different parts of herbs, the planting period and the cultivated geographic region.

\section{Identification of species and adulterants}

Different species may contain approximately the same components, while the contents of these components vary, which influence the therapeutic effect. Two leguminous plants, Astragalus membranaceus (Fisch.) Bge. var. mongholicus (bge.) Hsiao and Astragalus membranaceus (Fish.) Bge, are important medical herbs that share great similarities regarding their morphology, chemical constituents, and genomic DNA sequences. The identification of different medicinal species directly affects their pharmacological and clinical effects. Amplified AFLP-based genetic fingerprinting and GC-TOF/MS-based metabolic fingerprinting were used to successfully discriminate between the two species. The differences in some soluble sugars, fatty acids, proline, and polyamine reflected the plants' adaptation to different growth environments. Using multivariate and univariate statistical analyses, three AFLP markers and eight metabolites were identified as candidate DNA and metabolic markers to distinguish between the two herb materials [24]. In another study, metabolite profiling of five medicinal Panax herbs, which included P. ginseng (Chinese ginseng), P. notoginseng, P. japonicus, P. quinquefolium L., and $P$. ginseng (Korean ginseng), was performed using UPLC-QTOFMS and multivariate statistical analysis techniques. PCA of the analytical data showed that the five Panax herbs could be separated into five different groups of phytochemicals [25]. HPLC fingerprinting was used for comparison of three closely related species of Pericarpium Citri (Citrus reticulata 'Chachi', Citrus reticulata 'Dahongpao', and Citrus erythrosa Tanaka), and PLS-DA identified hesperidin, tangeretin, and nobiletin as potential biomarkers for their classification [26]. In a similar case, PCA and HCA as well as SIMCA and a BP-ANN were applied to identify and distinguish Epimedium wushanense and Epimedium koreanum based on their secondary metabolites. The SIMCA method failed to identify one sample, whereas BP-ANN precisely predicted the whole test set [27]. PCA was able to discriminate between ten Aristolochia species on the basis of their essential oil profiles, showing that $2 \mathrm{~h}$ of hydrodistillation produce the best outcome when the oils are used for discriminating between species [28]. Coincidentally, Sun et al. [29] drew on the same plant. In the Chinese Pharmaco- poeia 2010, only two Aconitum species are recorded. One is the root of Aconitum kusnezoffii Reichb., namely "Caowu" in Chinese. The other species was Aconitum carmichaelii Debx. Two herbal drugs are derived from this species. The two species were distinguished successfully using UPLC-QTOF-HDMS, combining with PCA and S-plot. Moreover, a PCA score plot clearly demonstrated discrimination between Artemisia annua and Artemisia afra on the basis of phenylpropanoids (caffeic acid, chlorogenic acid, dicaffeoyl quinic acid, and ferulic acid) [30]. Spectral fingerprinting via NIR has been utilized for the rapid identification and counterfeit detection of Eleutherococcus senticosus, and PCA, DA, SIMCA, and PLS-DA were found to allow good discrimination between $E$. senticosus and other herbs both related to and not related to the Araliaceae family [31]. PCA has been successfully applied for distinguishing Angelica sinensis from related Apiaceae (syn. Umbelliferae) herbs based on complete HPLC fingerprints [32]. The same biomarkers were recognized by PLS-DA for the discrimination of authentic Pericarpium Citri from commercial samples, mixed peel samples, and other citrus peels [33]. ${ }^{1} \mathrm{H}-\mathrm{NMR}$ spectroscopy and multivariate data analyses were applied to discriminate two Bupleurum species (B. chinense and B. scorzonerifolium) and to explore the influences of habitat and culture methods on the quality of Radix Bupleuri plants based on their metabonomic profiles [34]. The quality of Radix Bupleuri plants was evaluated via HPLC-ELSD analysis and HPTLC based on analysis of their principal bioactive components (saikosaponins). The acquired data were processed using ANNs and kNN to distinguish between different species of the genus [35]. DART-MS provides a novel mass spectrometric ion source by producing $[\mathrm{M}+\mathrm{H}]^{+}$molecular ion species. In analyses of Glycyrrhiza inflata Batalin, the peak at $\mathrm{m} / \mathrm{z} 339$ originates mainly from the $[\mathrm{M}+\mathrm{H}]^{+}$of $\mathrm{LA}$, a species-specific compound. These results indicate that $G$. inflata can be differentiated from the other two species based on detection of LA peaks using DART-MS analysis [36]. In addition, chromatographic fingerprinting via GC-MS coupled with SA and PCA has been undertaken for discriminating Scutellaria barbata D. Don from adulterants. The results showed that the samples could be identified based on differences between the samples and various adulterants [37]. Similarity analysis and HCA were applied for the first time to identify and distinguish genuine Aconitum kusnezoffii from its adulterants, which demonstrated the feasibility of linking the HCA approach to chemotaxonomic analysis on the basis of the presence of alkaloids [38]. To discriminate and assess the quality of Curcuma phaeocaulis, C. kwangsiensis, and C. wenyujin from different ecotypes, a metabonomics analysis was carried out via GC-MS coupled with multivariate statistical analysis. Characterization of phytochemicals in essential oils was performed by automated matching to the MS library and comparison of their mass spectra, which discriminated among the different plant parts [39]. Curcuma plants, such as Curcuma wenyujin Y.H. Chen et C. Ling and Curcuma longa L., were also distinguished successfully via HPLC-DAD-MS [40].

\section{Identification of different medicinal parts of herbs}

The choice of different parts of herbs determines the resulting curative effect, which is the purpose of therapy. The contents of the active components of diverse plant parts were identified. In the long history of the use of medicinal plant preparations, different plant parts have been regarded as different drugs. R. Jurišić Grubešić et al. [41] identified the variation in total polyphenol contents, employing Folin-Ciocalteu's reagent, between different parts of Plantago plants (leaves: up to $10.15 \%$; stems: up to 
4.34\%; and flowers: up to 5.56\%). The content of tannins in stems ranged from $0.28 \%$ to $1.00 \%$, while leaves and flowers contained tannins at concentrations of $2.26 \%$ and $2.21 \%$ based on UV-Vis spectrophotometry.

Metabolite profiling of different parts of Panax notoginseng was carried out using UPLC-ESI-MS and multivariate statistical analysis. PCA of the UPLC-ESI-MS data showed a clear separation of the compositions among the flower buds, roots, and rhizomes of $P$. notoginseng. The saponins accounting for these variations were identified based on corresponding loading weights and were further verified based on the accurate mass, tandem mass, and retention time of available standard saponins using UPLCQTOF-MS [42]. Moreover, each extract from 24 mulberry leaf samples, divided into six locations from the tip of the stem in each of four strains, was analyzed via pattern recognition methods, including PCA and SIMCA. The 24 extracts from mulberry leaves showed independent spectra in ${ }^{1} \mathrm{H}-\mathrm{NMR}$ analyses [43]. Aconitum carmichaelii Debx., another example for the application of plant metabonomics in the discrimination of different parts of herb plants, was studied by Sun et al. [29]. The mother root is named "Chuanwu", while the daughter or lateral root of Aconitum carmichaelii Debx. is known as "Shengfuzi". Shengfuzi has been prescribed more frequently than Chuanwu to treat rheumatic diseases. The analytical techniques, UPLC-Q-TOF-HDMS, as well as the data processing methods, PCA, and S-plot, were the main measures in this study.

\section{Differentiation of distinct cultivated geographic regions} The environments of the cultivated geographic regions of medicinal plants, including their temperature, humidity, soil, and climate, are determinant factors. Therefore, the cultivated geographic region influences the growth of herbs. Wei-Jun Kong et al. [44] utilized UPLC-PAD analysis to examine the five active alkaloids in Rhizoma Coptidis Chinensis, successfully grouping the plants in accordance with their province of origin. Moreover, the LS-SVM, RBF-ANN, PLS-DA, and kNN methods were applied for the classification of Rhizoma Corydalis, and in general, no statistically significant differences were found between these four methods. NIRS was used to identify Rhizoma Corydalis plants from two different geographical origins [45]. Another example of the application of the HCA technique was its use for the classification of Isatis indigotica roots collected from different regions based on HPLC fingerprinting [46]. Ganoderma lucidum samples from different cultivated geographic regions were evaluated using HPLC fingerprinting. The HCA, PCA, PLS-DA, and SIMCA techniques were employed to classify samples in accordance with their province of origin [47]. In addition, the essential oils of the Cinnamon Cortex specimens obtained from different localities have been analyzed via GC-MS [48]. Furthermore, the volatile oils of Artemisia capillaris Herba from different locations were investigated through GC-MS to develop a characteristic fingerprint of this raw herb [49]. The discrimination of Schizonepeta tenuifolia Briq. from different origins has also been achieved via PCA and HCA, which classified the samples into two main groups on the basis of five marker compounds [50]. It is also worth noting that the combination of NIR spectroscopy with DA and PLS-DA analysis was applied in geographical origin discrimination for Radix Scutellaria Baicalensis [51]. A nontargeted procedure was applied for ${ }^{1} \mathrm{H}-\mathrm{NMR}$ spectroscopic fingerprinting of extracts from Rhodiola rosea rhizomes for pattern recognition analysis and identification of secondary metabolites responsible for differences in sample composition. For this purpose, plants from three different geographic areas (the Swiss Alps, Finland, and the Altai region in Siberia) were investigated [52]. Furthermore, quantitative estimates of the major isoflavones in Pueraria lobata were produced, and the studied samples were classified through PCA based on the amounts of puerarin, daidzin, daidzein, and genistin present [53]. Metabolite fingerprinting was applied in an attempt to evaluate the quality of dried Angelica acutiloba roots. An enhanced understanding of the dominance of the relationship of the cultivation area with the evaluated quality was conceptualized and applied to the construction of a PLS-DA classification model, which provided the basis for accurate and reliable predictivity [54]. Additionally, PCA was performed using the data generated through HPLC-DAD-ELSD analysis for quality control of Polygala japonica from different localities in China [55]. Recently, Suzuki et al. [56] classified Sophora flavescens grown in Japan and China via NMR.

\section{Differentiation of distinct planting periods}

The planting period is also a vital factor in the quality of a crude drug due to the duration over which a plant obtains nutrition from the soil.

An UPLC-Q-TOF-MS-based metabolomic technique was applied for metabolite profiling in 60 Panax ginseng samples aged from 1 to 6 years [57]. Ginseng is an important herbal resource worldwide, and adulteration or falsification of the cultivation age has been a serious problem for ginseng in the commercial market. In this study, ginseng roots cultivated for 2-6 years under good agricultural practices standard guidelines were analyzed via NMRbased metabolomics techniques using two solvents [58]. Moreover, it has been demonstrated that July might be the best harvest time for Pericarpium Citri Reticulatae Viride, while November and December are better for Pericarpium Citri Reticulatae. Furthermore, hesperidin, nobiletin, and tangeretin were screened as chemical markers based on PCA loadings. The HPLC-HELP-PCA strategy has shown potential in the optimization of harvest times [26]. Recently, Xue et al. [59] utilized GC-MS to investigate the flower buds of Tussilago farfara in different development stages. Collectively, medicinal herbs from different species and the different parts of the same plant usually exhibit different efficacy, pharmacological actions, and clinical indications due to the significant differences in the types and quantity of the constituents. The species diversity seems to be a significant factor to influence the quality assessment. In addition, chemical constituents of the same plant may be various due to different cultivation areas, climatic conditions, and cultivation ages. For example, ginseng of cultivation ages from 4 to 6 years is the most demanded ginseng in the market. However, age and cultivation areas can hardly be determined by the herb's physical appearance alone. Accordingly, confused clinical application led to the consumption of incorrect forms of plant material, improper use, and undesirable effects. Hence, an effective method applied in quality control is urgently demanded for the identification step of medicinal herbs. Since some samples share similarities in morphology but with subtle variations in certain ingredients, metabonomics can provide a platform to use analytical techniques coupled with multivariate statistics for the differentiation of these complex samples. Metabonomics information not only assist in the establishment of a deeper understanding of the complex interactive nature of plant metabolic networks and their responses to environmental change but also provide unique insights into the fundamental nature of plant phenotypes in relation to development, physiology, tissue identity, resistance, biodiversity, and so on. To make them 
clear, the plant material, analysis technique, chemometrics methods, biomarkers, and bioactivity aspects are summarized in $\odot \mathrm{Ta}$ ble 2 .

\section{Processing}

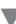

Processing is the second step in the production of Chinese medicinal preparations. TCM-specific production steps include storing, washing, rinsing, drying, remoistening, and cutting, and eventually, unique processing techniques, such as stir frying, steaming, or calcining are performed to satisfy different clinical therapeutic requirements. First, the effect of processing is thought to enhance the therapeutic efficiency in Sophora japonica L. [60]. Drug processing can also weaken the structure of plants so that the active components can be extracted easily. Additionally, additives react with the compounds present in plants generating new components dissolved in solvents. For instance, alkaloids dissolve in acidic solvents, so vinegar is widely applied to crude drugs to enrich alkaline substances. Second, processing has been reported to reduce the toxicity of the crude drugs, as described with Fuzi [61]. As evidence has accumulated, it has been shown that poisonous protein is one of the causes of accidental side effects. As proteins are thermo-sensitive, crude drugs should be subjected to heat treatment. Third, the expansion of applications is another important unexpected impact. Finally, after processing, the generation of several new compounds has been reported [62]. However, the dosage of additives and the time of heat treatment should be considered during processing, as they are the major factors that affect quality control.

In the large-scale production, it is difficult to guarantee the purity of all products. Researchers spend long periods finding solutions to quality control. The development of metabonomics has provided a necessary way to understand cellular responses to mutations at all levels of gene products [63]. In recent years, a wide range of metabonomic analytical techniques have been implemented in research on TCM [64]. Several cases illustrate the possibilities of the application of metabonomics in quality control during the processing of TCM materials. Ginseng has been employed in TCM for over two thousand years and is now widely used around the world as an elixir [63]. In Asia, there are two types of ginseng that are commonly found in the herbal medicine market: WG and RG. In the practice of traditional Chinese medicine, WG and RG have been used for different purposes. WG is traditionally produced via sun drying of fresh ginseng, and RG is manufactured by steaming fresh ginseng at $95-100^{\circ} \mathrm{C}$ for $2-3 \mathrm{~h}$ and then drying it. WG is used to "supply qi and promote the production of body fluids" as well as enhance physical fitness and disease resistance, while RG has a "warming effect" and is used for "boosting yang" and replenishing vital essence [64]. Ginsenosides Rb1, Rb2, Rc, Rd, Rg1, and Re are the major constituents of both WG and RG, while ginsenosides Rg3, Rg5, Rg6, Rh1, Rh2, Rk1, Rs3, and F4 are known to be unique constituents of RG [6572]. These unique ginsenosides found in RG have been reported to be converted from the ginsenosides found in fresh ginseng after steaming $[70,73,74]$. In one study, ginseng was processed under temperatures of 100,140 , and $180^{\circ} \mathrm{C}$, with or without vinegar; the duration of exposure to each temperature was 10,30 , and $50 \mathrm{~min}$, respectively, and there was a clear separation in the score plots obtained for the various treatment conditions. The major compounds contributing to the separation of $50 \%$ methanol extracts of vinegar-treated ginseng subjected to various pro- cessing conditions were valine, lactate, alanine, arginine, glucose, fructose, and sucrose. As the temperature increased, the valine, arginine, glucose, fructose, and sucrose concentrations decreased, whereas lactate, glucose, and fructose increased in the vinegar-treated samples compared to non-vinegar-treated samples [62]. Moreover, UPLC/TOFMS had been demonstrated to be a powerful tool for use in herbal metabonomics to discriminate differentially processed herbs, such as raw and steamed $P$. notoginseng [75]. An UHPLC-TOF-MS-based metabonomics platform coupled with PCA and PLS-DA was developed for Panax notoginseng to establish a correlation between the duration of steaming and the maximum production of bioactive ginsenosides [76]. A similar study was performed to determine chemical markers for discriminating between raw and processed Radix Rehmanniae samples [77]. In addition, the three types of products obtained from the processing of Ligustrum lucidum fruits have been distinguished, which correspond to steam treatment processing products, vinegar treatment processing products, and the fruits processed with wine. There are differences in metabolite profiles among the crude and different types of processed fruits of L. lucidum. Ligustaloside B was identified as a chemical marker for such variations, and its contents in crude L. lucidum specimens were found to be significantly higher than in processed samples. This study indicated that UPLC-QTOF-MS coupled with multivariate statistics is able to provide quality control for the crude and processed fruits of L. lucidum, and these results provide the basis for determining the appropriate mechanism of processing [78]. The products of the processing of Polygala Radix were also successfully distinguished [79]. One study was designed to perform a comprehensive metabonomics analysis of Fuzi and its processed products, Yanfuzi, Heishunpian, and Baifupian, via UPLC-Q-TOF-HDMS combined with pattern recognition methods. Differences in the metabolic profiles of Fuzi and its processed preparations were clearly observed based on PCA of the obtained MS spectra. Significant changes in 19 metabolite biomarkers were detected in the Fuzi samples and the three preparations [61]. Similarity analysis and PCA were applied to address the issue of the various quality changes that occur during the process of toasting Fructus Xanthii supplied by different producing areas. A high similarity was observed between different samples, which indicates that the proportion and distribution of the components in most extracts of $F$. xanthii show a high level of consistency [80]. HPLC fingerprints together with metal profiles were employed to assess the quality control procedures applied to Atractylis chinensis. A separate data matrix and combined data matrices were analyzed via PCA, kNN, and LDA. The PCA results from the combined data matrices indicated that the samples were discriminated on the basis of the applied processing methods. Within each group, the samples were reasonably well grouped according to their geographical origin and classification using kNN, and LDA results supported the PCA results [81].

As the raw and processed forms of herbs have different pharmacological actions, it is pertinent to administer the correct form of herb to avoid any undesirable consequences. Even the duration of the processing procedure, the processing adjuvants, and its dosage arouse the subtle changes in the contents of compounds. Therefore, it is of paramount importance to characterize the specific forms. The collection of quoted literature data is shown in - Table 2. 
Table 2 Application of plant metabonomics in TCM.

\begin{tabular}{|c|c|c|c|c|c|c|}
\hline $\begin{array}{l}\text { TCM } \\
\text { materials }\end{array}$ & $\begin{array}{l}\text { Pur- } \\
\text { pose }\end{array}$ & $\begin{array}{l}\text { Analysis } \\
\text { techniques }\end{array}$ & $\begin{array}{l}\text { Chemometrics } \\
\text { methods }\end{array}$ & Biomarkers & Bioactivity & Ref. \\
\hline $\begin{array}{l}\text { Two Astragalus } \\
\text { plants }\end{array}$ & A1 & GC-TOF/MS & AFLP & $\begin{array}{l}\text { Three AFLP markers, eight } \\
\text { metabolites }\end{array}$ & Antiperspirant and antidiuretic & [24] \\
\hline Five Panax plants & A1 & $\begin{array}{l}\text { UPLC- } \\
\text { QTOF-MS }\end{array}$ & PCA & $\begin{array}{l}\text { Ginsenoside Rf, Rb, Rb2, 20(s)- } \\
\text { pseudoginsenosidde, F11 }\end{array}$ & $\begin{array}{l}\text { Antineoplastic, hypolipidemic } \\
\text { agents* }\end{array}$ & [25] \\
\hline $\begin{array}{l}\text { Panax } \\
\text { notoginseng }\end{array}$ & A2 & $\begin{array}{l}\text { UPLC- } \\
\text { QTOF-MS }\end{array}$ & PCA & Saponins & $\begin{array}{l}\text { Prevention and treatment of cere- } \\
\text { brovascular diseases, immune regu- } \\
\text { lation, heap to protection, anticarci- } \\
\text { nogenesis, neuroprotective effect }\end{array}$ & [42] \\
\hline Panax ginseng & A4 & $\begin{array}{l}\text { UPLC- } \\
\text { QTOF-MS }\end{array}$ & $\begin{array}{l}\text { PCAHCA RF PAM } \\
\text { PLS-DA }\end{array}$ & 1 & 1 & [57] \\
\hline Panax ginseng & B & $\begin{array}{l}\text { UPLC- } \\
\text { QTOF-MS }\end{array}$ & PCA & 1 & 1 & [62] \\
\hline $\begin{array}{l}\text { Panax } \\
\text { notoginseng }\end{array}$ & B & $\begin{array}{l}\text { UPLC- } \\
\text { QTOF-MS }\end{array}$ & PCA, PLS-DA & 1 & 1 & [76] \\
\hline Panax ginseng & A4 & NMR & PCA, PLS-DA & $\begin{array}{l}\text { Amino acids, organic acids, } \\
\text { sugars }\end{array}$ & $\begin{array}{l}\text { Cardiovascular control of blood } \\
\text { pressure }\end{array}$ & [58] \\
\hline $\begin{array}{l}\text { Three tangerine } \\
\text { peels }\end{array}$ & $\mathrm{A} 1,4$ & HPLC-DAD & PCA, HELP & $\begin{array}{l}\text { Hesperidin, tangeretin, } \\
\text { nobiletin }\end{array}$ & $\begin{array}{l}\text { Protective effect on myocardial } \\
\text { ischemia }\end{array}$ & [26] \\
\hline Mallotus plants & $\begin{array}{l}\mathrm{A} 1,2, \\
3\end{array}$ & LC-MS & PLS-DA & Senkyunolide A & Antioxidants & $\begin{array}{l}{[33,} \\
109]\end{array}$ \\
\hline $\begin{array}{l}\text { Two Epimedium } \\
\text { plants }\end{array}$ & A1 & HPLC & $\begin{array}{l}\text { PCA,HCA,SIMCA, } \\
\text { BP-ANN }\end{array}$ & Flavonoids & $\begin{array}{l}\text { Influence on sexual function, anti- } \\
\text { aging, effect on immune system, } \\
\text { anti-inflammatory, antitussive, } \\
\text { expectorant, antiasthma }\end{array}$ & [27] \\
\hline Rhizoma Coptidis & A3 & UPLC & SA, HCA, PCA & $\begin{array}{l}\text { Berberine, coptisine, } \\
\text { palmatine, jateorrhizine, } \\
\text { epiberberine }\end{array}$ & $\begin{array}{l}\text { Efficacy of suppressing fever, dispel- } \\
\text { ling dampness, removing toxicosis } \\
\text { and anti-microbes* }\end{array}$ & [44] \\
\hline $\begin{array}{l}\text { Five Bupleurum } \\
\text { plants }\end{array}$ & $\mathrm{A} 1$ & $\begin{array}{l}{ }^{1} \mathrm{H}-\mathrm{NMR} \\
\text { HPLC-ELSD } \\
\text { HPTLC }\end{array}$ & ANNs, kNN & Saikosaponins & $\begin{array}{l}\text { Anti-inflammatory, antineoplastic, } \\
\text { immunosuppressive agents* }\end{array}$ & $\begin{array}{l}{[34]} \\
{[35]}\end{array}$ \\
\hline $\begin{array}{l}\text { Ten Aristolochia } \\
\text { plants }\end{array}$ & A1 & GC-MS & PCA & Essential oils & $\begin{array}{l}\text { Abortifacients, stomachics, anti- } \\
\text { ophidians, antiasthmatics, expecto- } \\
\text { rants, slimming therapies }\end{array}$ & [28] \\
\hline $\begin{array}{l}\text { Two Artemisia } \\
\text { plants }\end{array}$ & $\mathrm{A} 1$ & NMR & PCA & Polar components & Antiplasmodial & [30] \\
\hline $\begin{array}{l}\text { Artemisia capillaris } \\
\text { herba }\end{array}$ & A3 & GC-MS & EWOP, FSMWEFA & Essential oils & $\begin{array}{l}\text { Choleretic, anti-inflammatory and } \\
\text { diuretic agent in the treatment of } \\
\text { epidemic hepatitis }\end{array}$ & [49] \\
\hline $\begin{array}{l}\text { Three Curcuma } \\
\text { plants }\end{array}$ & $\mathrm{A} 1$ & GC-MS & PCA, PLS-DA & Essential oils & $\begin{array}{l}\text { Against skin diseases, colic inflam- } \\
\text { matory disorders, insect repellants, } \\
\text { antimicrobial }\end{array}$ & [39] \\
\hline $\begin{array}{l}\text { Two Curcuma } \\
\text { plants }\end{array}$ & $\mathrm{A} 1$ & $\begin{array}{l}\text { HPLC-DAD- } \\
\text { MS, GC-MS }\end{array}$ & PCA & $\begin{array}{l}\text { Curcumin, demethoxycurcu- } \\
\text { min, bisdemethoxycurcumin, } \\
\text { dihydrocurcumin, ar-turmer- } \\
\text { one, } \alpha, \beta \text {-turmerone, zingiber- } \\
\text { ene }\end{array}$ & $\begin{array}{l}\text { Against skin diseases, colic inflam- } \\
\text { matory disorders, insect repellants, } \\
\text { antimicrobial, antidiabetic medica- } \\
\text { tions }\end{array}$ & [40] \\
\hline $\begin{array}{l}\text { Rhizoma } \\
\text { Corydalis }\end{array}$ & A3 & NIRS & $\begin{array}{l}\text { WT, LS-SVM, PLS-DA, } \\
\text { KNN }\end{array}$ & 1 & 1 & [45] \\
\hline $\begin{array}{l}\text { Eleutherococcus } \\
\text { senticosus }\end{array}$ & $\mathrm{A} 1$ & NIRS & $\begin{array}{l}\text { PCA, DA, SIMCA and } \\
\text { PLS-DA }\end{array}$ & 1 & 1 & [31] \\
\hline Angelica sinensis & A1 & HPLC & PCA & Senkyunolide A & Treatment of gynecological diseases & [32] \\
\hline Plantago L. & $\mathrm{A} 2$ & UV & UPGMA, PCA & Polyphenols, tannins & Diuretic & [41] \\
\hline $\begin{array}{l}\text { Three Glycyrrhiza } \\
\text { plants }\end{array}$ & $\mathrm{A} 1$ & DART-MS & 1 & Licochalcone A & $\begin{array}{l}\text { Antimicrobial activity, antiplasmo- } \\
\text { dial activity, antileishmanial activity* }\end{array}$ & [36] \\
\hline Mulberry leaf & A3 & ${ }^{1} \mathrm{H}-\mathrm{NMR}$ & PCA, SIMCA & 1 & 1 & [43] \\
\hline Isatis indigotica & A3 & RP-HPLC & HCA & Indirubin, indigotin & $\begin{array}{l}\text { Anti-inflammatory, inhibition of } \\
\text { leucine-rich repeat kinase-2, prolif- } \\
\text { erative and androgenic effects* }\end{array}$ & [46] \\
\hline $\begin{array}{l}\text { Cortex } \\
\text { Cinnamomi }\end{array}$ & A3 & GC-MS & IOP, HELP, SFA, OPR & Essential oils & Antimicrobial activities & $\begin{array}{l}{[48,} \\
110]\end{array}$ \\
\hline $\begin{array}{l}\text { Ganoderma } \\
\text { lucidum }\end{array}$ & A3 & NIRS & $\begin{array}{l}\text { HCA, PCA, PLS-DA, } \\
\text { SIMCA }\end{array}$ & $\begin{array}{l}\text { Triterpenoidsaponins, poly- } \\
\text { saccharides }\end{array}$ & $\begin{array}{l}\text { Inhibitors of the in vitro human } \\
\text { recombinant aldose reductase* }\end{array}$ & [47] \\
\hline
\end{tabular}




\begin{tabular}{|c|c|c|c|c|c|c|}
\hline $\begin{array}{l}\text { TCM } \\
\text { materials }\end{array}$ & $\begin{array}{l}\text { Pur- } \\
\text { pose }\end{array}$ & $\begin{array}{l}\text { Analysis } \\
\text { techniques }\end{array}$ & $\begin{array}{l}\text { Chemometrics } \\
\text { methods }\end{array}$ & Biomarkers & Bioactivity & Ref. \\
\hline $\begin{array}{l}\text { Schizonepeta } \\
\text { tenuifolia Briq. }\end{array}$ & A3 & GC-MS & PCA,HCA & $\begin{array}{l}\text { 2-Hydroxy-2-isopropenyl-5- } \\
\text { methylc, cis-pulegone oxide, } \\
\text { menthone, pulegone, cyclo- } \\
\text { hexanone, schizonal }\end{array}$ & $\begin{array}{l}\text { Antifungal properties, decrease in } \\
\text { ambulation, and increase in pento- } \\
\text { barbital-induced sleeping time }\end{array}$ & $\begin{array}{l}{[50,} \\
111]\end{array}$ \\
\hline $\begin{array}{l}\text { Scutellaria } \\
\text { barbata D. Don }\end{array}$ & $\mathrm{A} 1$ & GC-MS & SA, PCA & 86 Compounds & $\begin{array}{l}\text { Antimicrobial, protecting liver and } \\
\text { biliary }\end{array}$ & [37] \\
\hline $\begin{array}{l}\text { Radix Scutellaria } \\
\text { Baicalensis }\end{array}$ & A3 & NIR & DA, S-DA & 1 & 1 & [51] \\
\hline $\begin{array}{l}\text { Rhodiola rosea } \\
\text { rhizomes }\end{array}$ & A3 & ${ }^{1} \mathrm{H}-\mathrm{NMR}$ & PCA & Salidroside,rosavin & $\begin{array}{l}\text { Protective effects on LPS-induced } \\
\text { acute lung injury* }\end{array}$ & [52] \\
\hline Pueraria lobata & A3 & RRLC & PCA & Isoflavonoids & $\begin{array}{l}\text { Antioxidant, estrogen-like effect, } \\
\text { and treatment of osteoporosis }\end{array}$ & $\begin{array}{l}{[53,} \\
112] \\
{[113]}\end{array}$ \\
\hline Angelica acutiloba & A3 & $\begin{array}{l}\text { Pyrolyser- } \\
\text { coupled } \\
\text { (PY-GC-MS) }\end{array}$ & PCA, PLS-DA & 1 & 1 & [54] \\
\hline Polygala japonica & A3 & $\begin{array}{l}\text { HPLC-DAD- } \\
\text { ELSD }\end{array}$ & PCA, COW & 1 & 1 & [55] \\
\hline $\begin{array}{l}\text { Sophora } \\
\text { flavescens }\end{array}$ & A3 & NMR & PCA & Kurarinol & $\begin{array}{l}\text { Relative inhibition or inhibition of } \\
\text { phosphodiesterase } 3,4,5^{*}\end{array}$ & [56] \\
\hline Tussilago farfara & A4 & GC-MS & PCA & $\begin{array}{l}\text { Fifty-four metabolites were } \\
\text { identified, including } 35 \text { polar } \\
\text { metabolites and } 19 \text { nonpolar } \\
\text { compounds }\end{array}$ & 1 & [59] \\
\hline $\begin{array}{l}\text { Atractylis } \\
\text { chinensis DC }\end{array}$ & B & HPLC & PCA, kNN, LDA & 1 & 1 & [81] \\
\hline $\begin{array}{l}\text { Aconitum } \\
\text { kusnezoffii }\end{array}$ & $\mathrm{A} 1$ & HPLC & HCA & $\begin{array}{l}\text { Mesaconitine, aconitine, } \\
\text { hypaconitine }\end{array}$ & $\begin{array}{l}\text { Voltage-gated sodium channel } \\
\text { agonists, immunologic* }\end{array}$ & [38] \\
\hline Fuzi & B & $\begin{array}{l}\text { UPLC-Q-TOF- } \\
\text { HDMS }\end{array}$ & $\begin{array}{l}\text { PCA, PLS-DA, } \\
\text { OPLS-DA }\end{array}$ & $\begin{array}{l}\text { Aconitine, mesaconitine, } \\
\text { hypaconitine, deoxyaconitine, } \\
\text { 10-OH-mesaconitine }\end{array}$ & $\begin{array}{l}\text { Voltage-gated sodium channel } \\
\text { agonists, immunologic* }\end{array}$ & [61] \\
\hline $\begin{array}{l}\text { Two Carmichaelii } \\
\text { plants }\end{array}$ & $\mathrm{A} 1, \mathrm{~B}$ & $\begin{array}{l}\text { UPLC-Q-TOF- } \\
\text { HDMS }\end{array}$ & PCA, S-plot & 22 Types of alkaloids & $\begin{array}{l}\text { Voltage-gated sodium channel } \\
\text { agonists, immunologic* }\end{array}$ & [29] \\
\hline $\begin{array}{l}\text { Radix } \\
\text { Rehmanniae }\end{array}$ & B & $\begin{array}{l}\text { UHPLC- } \\
\text { TOFMS }\end{array}$ & PCA, OPLS-DA & $\begin{array}{l}\text { Leonurideor, its isomer, } \\
\text { 5-GGMF }\end{array}$ & $\begin{array}{l}\text { Antitumor, antidiabetic, neuro- } \\
\text { protective* }^{*}\end{array}$ & [77] \\
\hline $\begin{array}{l}\text { Ligustrum } \\
\text { lucidum }\end{array}$ & B & $\begin{array}{l}\text { UPLC- } \\
\text { QTOF-MS }\end{array}$ & PCA & Ligustaloside B & Antidiabetic, antioxidant & $\begin{array}{l}{[78,} \\
114]\end{array}$ \\
\hline Fructus Xanthii & B & GC-MS & PCA & 14 Polar compounds & $\begin{array}{l}\text { Treatment of cramping and numb- } \\
\text { ness of the limbs, ulcer, sinusitis, } \\
\text { catarrhs and pruritus }\end{array}$ & [80] \\
\hline
\end{tabular}

* Activity obtained from PubChem (http://www.ncbi.nlm.nih.gov/pccompound). A1: Identification of species and adulterants; A2: identification of different medicinal parts of herbs; A3: differentiation of distinct cultivated geographic regions; A4: differentiation of distinct planting periods; B: processing

\section{Pharmaceuticals}

The last step in the production of Chinese medicinal preparations, obtaining plant extracts, can also be subjected to quality control using metabonomic profiles. The extract is a contributing factor to the quality and toxicity of the drug produced. However, a prerequisite is that the extracts of intermediate products that are to be analyzed are well documented with regard to the production steps they have been subjected to. Bioactive compounds may be identified if it is possible to obtain or generate extracts of different materials from the same plant species that are highly variable in bioactivity. PCA may then be used to discriminate the chemical fingerprints of the extracts in a way that separates them by their activity or by spatial origin, and relevant chemical compounds can subsequently be deduced from their contributions to the respective fingerprints $[82,83]$. The majority of TCM products for oral use are applied as water decoctions [84]. Other oral prep- arations include macerates in aqueous ethanol and powdered drugs suspended in water or prepared in pills, with honey, water, or rice gruel as an excipient $[85,86]$. An HPLC fingerprinting analysis was developed to assess the quality and comparative contents of cinnamon bark and cinnamon twig components. PCA and PLS-DA allowed good discrimination of these samples, and cinnamaldehyde was found to be the most abundant marker component [87]. Several examples are found in the literature of utilizing HPLC together with different chemometric methods for the analysis of complex mixtures, including the resolution of HPLC fingerprints of complex, many-component substances found in Huoxiang Zhengqi tincture samples from a batch from a given manufacturer, or from different producers [88]. Another example of investigating complex mixtures is the analysis of nine bioactive compounds from a Yiqing preparation which is composed of three TCMs, to assess the consistency of the quality among 12 manufacturers based on SA. The results showed that 
HPLC fingerprinting could serve as the first tool for revealing the consistency of the quality of Yiqing via similarity comparisons [89]. LC-LTQ-Orbitrap MS was applied for the simultaneous identification and quantification of multi-constituent Xin-Ke-Shu, a TCM preparation [90].

It is complicated during the pharmaceutical process. On the one hand, the pharmaceutical excipients hold back the analysis. On the other hand, a Chinese patent drug usually consists of many sorts of herbs; the constituents' analysis is a bottleneck in quality control. Plant metabonomics, a platform aimed at the complex ingredients, can help to better understand the nature of these problems.

\section{Conclusions and Perspectives \\ $\nabla$}

Plant metabonomics can be applied in the discrimination, processing, and pharmaceutical preparation steps of TCM products, which represent the entire production process ( $\odot$ Table 2 ). As the first step in the production of Chinese medicinal preparations, the identification of plant varieties used, involving species, parts of the herbs, cultivated geographic region, and planting period, is of great significance for ensuring the safety and effectiveness of clinical treatment since the quality and contents of the active constituents depend on these factors. Adulterants are assumed to be distinguishable from plant materials and play the role of challenging substances. The processing, as the second step in production, appears to be of significance in clinical applications and has been proven to satisfy the requirements of therapeutics. As different forms of TCMs show different pharmacological actions, it is pertinent to administer the correct form of herbs to avoid any undesirable consequences. Therefore, it is of paramount importance to characterize the specific form of TCM. Metabonomics can also be applied to control the content of extracts, which is crucial to the pharmaceutical production. The complexity and diversity of the components of TCM preparations make qualitative analyses difficult. In the pharmacopeia, single-component analysis is used on TCM mostly. Nevertheless, it lacks representativeness. In contrast to single-component analyses, metabonomics achieves comprehensive scans, addressing some of the shortfalls of single-component analysis. As shown by the three points we have just illustrated, plant metabonomics can play a vital role in quality assessments during the large-scale production of TCM preparations.

To facilitate the application of plant metabonomics in the quality assessment, on the one hand, we are supposed to utilize the new and effective techniques so that they will support metabonomics studies adequately. On the other hand, exploring potential research points of metabonomics in TCM seems necessary. With the appearance of RRLC and UFLC, the methods of analysis come to a new era. Shorter analysis time and the more efficient separation are the advantages of these methods [91]. MAS-NMR, another sharp technique, enhances the resolution of solid samples and plays an important role in the overlap of peaks [92]. Cristina Daolio et al. [93] applied MAS-NMR classifying commercial catuaba successfully. An LC-MS-NMR platform was demonstrated, which combines two innovations in microscale analysis, nanoSplitter LC-MS and microdroplet NMR, for the identification of unknown compounds found at low concentrations in complex sample matrixes as frequently encountered in metabonomics or natural product discovery [94]. Therefore, in the future, employing new and effective chromatographic or spectroscopic techniques for metabonomics studies seems to be an important tendency. What concerns exploring potential research points, in recent years, metabonomics was reported to the study of pharmacology in some terms. Employing a metabonomics platform, Yiqing Lin et al. [94] identified the active cyanobacterial metabolite. Kashif Ali et al. [95] also managed to screen the anti-TNF $\alpha$ activity in crude extracts of grapes and other berries by NMR spectroscopy and chemometric. Using this approach, compounds related to activity can be identified without extensive and elaborate chromatographic separation, and it thus allows rapid identification of extracts with biological activity. Moreover, screening the active compounds and effective parts seems to grow into a vital process in future studies. As a consequence, the results of quantitative assays will become more instructive and convincing. In a word, with the development of analysis methods and the exploration of potential research points, the application of metabonomics in TCM quality assessment tends to become more prevalent and considered in the future.

\section{Acknowledgements \\ $\nabla$}

This study was financially supported by the National Natural Science Foundation of China (Projects No.81001623 and No. 30902000).

\section{Conflict of Interest}

$\nabla$

No conflicts of interest exist.

\section{References}

1 Nicholson JK, Wilson ID. Opinion: understanding 'global' systems biology: metabonomics and the continuum of metabolism. Nat Rev Drug Discov 2003; 2: 668-676

2 Hui-Ru T, Yu-Lan W. Metabonomics: a revolution in progress. Prog Biochem Biophys 2006; 33: 401-417

3 Dong J, Xu L, Cao H, Dai X, Li X, Yang S, Chen Z. A new data processing method for metabonomic and its application in a study of diabetes. Chin J Magn Reson 2007; 24: 393

4 Lu YH, Hao HP, Wang GJ, Chen XH, Zhu XX, Xiang BR, Huang Q AJY. Metabolomics approach to the biochemical differentiation of Traditional Chinese Medicine syndrome types of hypertension. Chin J Clin Pharmacol Ther 2007; 12: 1144-1150

5 Cheng LL, Chang IW, Louis DN, Gonzalez RG. Correlation of high-resolution magic angle spinning proton magnetic resonance spectroscopy with histopathology of intact human brain tumor specimens. Cancer Res 1998; 58: 1825-1832

6 Cheng L, Ma M, Becerra L, Ptak T, Tracey I, Lackner A, Gonzalez R. Quantitative neuropathology by high resolution magic angle spinning proton magnetic resonance spectroscopy. Proc Natl Acad Sci US A 1997; 94: 6408-6413

7 Lao YM, Jiang JG, Yan L. Application of metabonomic analytical techniques in the modernization and toxicology research of traditional Chinese medicine. Br J Pharmacol 2009; 157: 1128-1141

$8 \mathrm{Kim}$ N, Kim K, Choi BY, Lee DH, Shin YS, Bang KH, Cha SW, Lee JW, Choi HK, Jang DS. Metabolomic approach for age discrimination of Panax ginseng using UPLC-Q-Tof MS. J Agric Food Chem 2011; 59: 1043510441

9 Holmes E, Wilson ID, Nicholson JK. Metabolic phenotyping in health and disease. Cell 2008; 134: 714-717

10 Yuliana ND, Khatib A, Choi YH, Verpoorte R. Metabolomics for bioactivity assessment of natural products. Phytother Res 2010; 25: 157-169

11 Nobeli I, Thornton JM. A bioinformatician's view of the metabolome. Bioessays 2006; 28: 534-545

12 Wold S, Sjöström M, Eriksson L. PLS-regression: a basic tool of chemometrics. Chemom Intell Lab Syst 2001; 58: 109-130 
13 Gabrielsson J, Jonsson H, Airiau C, Schmidt B, Escott R, Trygg J. OPLS methodology for analysis of pre-processing effects on spectroscopic data. Chemom Intell Lab Syst 2006; 84: 153-158

14 Wold S, Trygg J, Berglund A, Antti H. Some recent developments in PLS modeling. Chemom Intell Lab Syst 2001; 58: 131-150

15 Ceglarek U, Leichtle A, Brügel M, Kortz L, Brauer R, Bresler K, Thiery J, Fiedler GM. Challenges and developments in tandem mass spectrometry based clinical metabolomics. Mol Cell Endocrinol 2009; 301: 266271

16 Hastings CA, Norton SM, Roy S. New algorithms for processing and peak detection in liquid chromatography/mass spectrometry data. Rapid Commun Mass Spectrom 2002; 16: 462-467

17 Danielsson R, Bylund D, Markides KE. Matched filtering with background suppression for improved quality of base peak chromatograms and mass spectra in liquid chromatography-mass spectrometry. Anal Chim Acta 2002; 454: 167-184

18 Andreev VP, Rejtar T, Chen HS, Moskovets EV, Ivanov AR, Karger BL. A universal denoising and peak picking algorithm for LC-MS based on matched filtration in the chromatographic time domain. Anal Chem 2003; 75: 6314-6326

19 Bueschl C, Kluger B, Berthiller F, Lirk G, Winkler S, Krska R, Schuhmacher $R$. MetExtract: a new software tool for the automated comprehensive extraction of metabolite-derived LC/MS signals in metabolomics research. Bioinformatics 2012; 28: 736-738

20 Mok DKW, Chau FT. Chemical information of Chinese medicines: A challenge to chemist. Chemom Intell Lab Syst 2006; 82: 210-217

21 Xie P, Chen S, Liang YZ, Wang X, Tian R, Upton R. Chromatographic fingerprint analysis-a rational approach for quality assessment of traditional Chinese herbal medicine. J Chromatogr A 2006; 1112: 171-180

22 Li L, Sun B, Zhang Q Fang J, Ma K, Li Y, Chen H, Dong F, Gao Y, Li F, Yan X. Metabonomic study on the toxicity of Hei-Shun-Pian, the processed lateral root of Aconitum carmichaelii Debx. (Ranunculaceae). J Ethnopharmacol 2008; 116: 561-568

23 Zhang A, Sun H, Wang P, Han Y, Wang X. Recent and potential developments of biofluid analyses in metabolomics. J Proteom 2012; 75: 1079-1088

24 Duan LX, Chen TL, Li M, Chen M, Zhou YQ Cui GH, Zhao AH, Jia W, Huang $L Q, Q i X$. Use of the metabolomics approach to characterize Chinese medicinal material Huangqi. Mol Plant 2012; 5: 376-386

25 Xie G, Plumb R, Su M, Xu Z, Zhao A, Qiu M, Long X, Liu Z, Jia W. Ultra-performance LC/TOF MS analysis of medicinal Panax herbs for metabolomic research. J Sep Sci 2008; 31: 1015-1026

26 Yi L, Yuan D, Liang Y, Xie P, Zhao Y. Fingerprinting alterations of secondary metabolites of tangerine peels during growth by HPLC-DAD and chemometric methods. Anal Chim Acta 2009; 649: 43-51

27 Wang L, Wang X, Kong L. Automatic authentication and distinction of Epimedium koreanum and Epimedium wushanense with HPLC fingerprint analysis assisted by pattern recognition techniques. Biochem Syst Ecol 2012; 40: 138-145

28 Francisco CS, Messiano GB, Lopes LM, Tininis AG, de Oliveira JE, Capellari $J r$. L Classification of Aristolochia species based on GC-MS and chemometric analyses of essential oils. Phytochemistry 2008; 69: 168-175

29 Sun $H$, Wang $M$, Zhang A, Ni B, Dong H, Wang X. UPLC-Q-TOF-HDMS analysis of constituents in the root of two kinds of Aconitum using a metabolomics approach. Phytochem Anal 2013; 24: 263-276

30 Liu NQ Cao M, Frederich M, Choi YH, Verpoorte R, van der Kooy F. Metabolomic investigation of the ethnopharmacological use of Artemisia afra with NMR spectroscopy and multivariate data analysis. J Ethnopharmacol 2010; 128: 230-235

31 Lucio-Gutiérrez JR, Coello J, Maspoch S. Application of near infrared spectral fingerprinting and pattern recognition techniques for fast identification of Eleutherococcus senticosus. Food Res Int 2011; 44: 557-565

32 Lu GH, Chan K, Liang YZ, Leung K, Chan CL, Jiang ZH, Zhao ZZ. Development of high performance liquid chromatographic fingerprints for distinguishing Chinese Angelica from related Umbelliferae herbs. J Chromatogr A 2005; 1073: 383-392

33 Tistaert C, Dejaegher B, Chataigne G, Van Minh C, Quetin-Leclercq J, Vander Heyden $Y$. Dissimilar chromatographic systems to indicate and identify antioxidants from Mallotus species. Talanta 2011; 83: 11981208

34 Qin X, Dai Y, Liu NQ Li Z, Liu X, Hu J, Choi YH, Verpoorte R. Metabolic fingerprinting by (1)H-NMR for discrimination of the two species used as Radix Bupleuri. Planta Med 2012; 78: 926-933
35 Tian RT, Xie PS, Liu HP. Evaluation of traditional Chinese herbal medicine: Chaihu (Bupleuri Radix) by both high-performance liquid chromatographic and high-performance thin-layer chromatographic fingerprint and chemometric analysis. J Chromatogr A 2009; 1216: 2150-2155

36 Fukuda E, Baba M, Iwasaki N, Uesawa Y, Arifuku K, Kamoe O, Tsubono K, Okada Y. Identification of Glycyrrhiza species by direct analysis in real time mass spectrometry. Nat Prod Commun 2010; 5: 1755-1758

37 Pan R, Guo F, Lu H, Feng WW, Liang YZ. Development of the chromatographic fingerprint of Scutellaria barbatan D. Don by GC-MS combined with chemometrics methods. J Pharm Biomed Anal 2011; 55: 391-396

38 Zhao YY, Zhang Y, Lin RC, Sun WJ. An expeditious HPLC method to distinguish Aconitum kusnezoffii from related species. Fitoterapia 2009; 80: $333-338$

39 Xiang Z, Wang XQ Cai XJ, Zeng S. Metabolomics study on quality control and discrimination of three Curcuma species based on gas chromatograph-mass spectrometry. Phytochem Anal 2011; 22: 411-418

$40 \mathrm{Wu} H W$. Studies on warm and cold nature of JiangHuang and Yujin based on metabonomics [dissertation]. Beijing: Chinese Academy of Chinese Medical Sciences; 2011

41 Grubesić RJ, Vukovic J, Kremer D, Vladimir-Knezevic S. Spectrophotometric method for polyphenols analysis: prevalidation and application on Plantago L. species. J Pharm Biomed Anal 2005; 39: 837-842

42 Dan M, Su M, Gao X, Zhao T, Zhao A, Xie G, Qiu Y, Zhou M, Liu Z, Jia W. Metabolite profiling of Panax notoginseng using UPLC-ESI-MS. Phytochemistry 2008; 69: 2237-2244

43 Fukuda E, Yoshida M, Baba M, Uesawa Y, Suzuki R, Kamo O, Tsubono K, Arifuku K, Yatsunami K, Okada Y. Application to classification of mulberry leaves using multivariate analysis of proton NMR metabolomic data. Nat Prod Commun 2011; 6: 1621-1625

44 Kong WJ, Zhao YL, Xiao XH, Jin C, Li ZL. Quantitative and chemical fingerprint analysis for quality control of rhizoma Coptidischinensis based on UPLC-PAD combined with chemometrics methods. Phytomedicine 2009; 16: 950-959

45 Lai Y, Ni Y, Kokot S. Discrimination of Rhizoma Corydalis from two sources by near-infrared spectroscopy supported by the wavelet transform and least-squares support vector machine methods. Vib Spectrosc 2011; 56: 154-160

46 Zou P, Hong Y, Koh HL. Chemical fingerprinting of Isatis indigotica root by RP-HPLC and hierarchical clustering analysis. J Pharm Biomed Anal 2005; 38: 514-520

47 Chen Y, Xie MY, Yan Y, Zhu SB, Nie SP, Li C, Wang YX, Gong XF. Discrimination of Ganoderma lucidum according to geographical origin with near infrared diffuse reflectance spectroscopy and pattern recognition techniques. Anal Chim Acta 2008; 618: 121-130

48 Gong F, Liang YZ, Xu QS, Chau FT. Gas chromatography-mass spectrometry and chemometric resolution applied to the determination of essential oils in Cortex cinnamomi. J Chromatogr A 2001; 905: 193-205

49 Guo FQ Liang YZ, Xu CJ, Li XN, Huang LF. Analyzing of the volatile chemical constituents in Artemisia capillaris herba by GC-MS and correlative chemometric resolution methods. J Pharm Biomed Anal 2004; 35: 469-478

50 Jung JH, Hong J. GC/MS combined with chemometrics methods for quality control of Schizonepeta tenuifolia Briq: Determination of essential oils. Microchem J 2011; 97: 274-281

$51 \mathrm{Li}$ W, Xing L, Cai Y, Qu H. Classification and quantification analysis of Radix scutellariae from different origins with near infrared diffuse reflection spectroscopy. Vib Spectrosc 2011; 55: 58-64

52 Ioset KN, Nyberg NT, Van Diermen D, Malnoe P, Hostettmann K, Shikov AN, Jaroszewski JW. Metabolic profiling of Rhodiola rosea rhizomes by (1)H-NMR spectroscopy. Phytochem Anal 2011; 22: 158-165

53 Zhao C, Chan HY, Yuan D, Liang Y, Lau TY, Chau FT. Rapid simultaneous determination of major isoflavones of Pueraria lobata and discriminative analysis of its geographical origins by principal component analysis. Phytochem Anal 2011; 22: 503-508

54 Tianniam S, Bamba T, Fukusaki E. Pyrolysis GC-MS-based metabolite fingerprinting for quality evaluation of commercial Angelica acutiloba roots. J Biosci Bioeng 2010; 109: 89-93

55 Wang $H L$, Yao WF, Zhu DN, Hu YZ. Chemical fingerprinting by HPLC-DAD-ELSD and principal component analysis of Polygala japonica from different locations in China. Chin J Nat Med 2010; 8: 343-348

56 Suzuki R, Ikeda Y, Yamamoto A, Saima T, Fujita T, Fukuda T, Fukuda E, Baba M, Okada Y, Shirataki Y. Classification using NMR-based metabolomics of Sophora flavescens grown in Japan and China. Nat Prod Commun 2012; 7: 1453-1455 
57 Kim N, Kim K, Choi BY, Lee D, Shin YS, Bang KH, Cha SW, Lee JW, Choi HK, Jang DS. Metabolomic approach for age discrimination of Panax ginseng using UPLC-Q-Tof MS. J Agric Food Chem 2011; 59: 10435-10 441

58 Yang SO, Shin YS, Hyun SH, Cho S, Bang KH, Lee D, Choi SP, Choi HK. NMRbased metabolic profiling and differentiation of ginseng roots according to cultivation ages. J Pharm Biomed Anal 2012; 58: 19-26

59 Xue SY, Wang XJ, Sun HF, Zhang LZ, Qin XM, Li ZY. Metabolomic study of flower buds of Tussilago farfara in different development stages by GC-MS. Zhongguo Zhong Yao Za Zhi 2012; 37: 2863-2869

60 Wang JH, Wang ZH. Studies on enhancing therapeutic action of processing Chinese crude drugs. Lishizhen J Tradit Chin Med Res 1997; 8: 67-68

61 Sun H, Ni B, Zhang A, Wang M, Dong H, Wang X. Metabolomics study on Fuzi and its processed products using ultra-performance liquid-chromatography/electrospray-ionization synapt high-definition mass spectrometry coupled with pattern recognition analysis. Analyst 2012; 137: 170-185

62 Kim SH, Hyun SH, Yang SO, Choi HK, Lee BY. (1)H-NMR-based discrimination of thermal and vinegar treated ginseng roots. J Food Sci 2010; 75: C577-C581

63 Angelova N, Kong HW, van der Heijden R, Yang SY, Choi YH, Kim HK, Wang $M$, Hankemeier T, van der Greef J, Xu G, Verpoorte R. Recent methodology in the phytochemical analysis of ginseng. Phytochem Anal 2008; 19: 2-16

64 Zhang HM, Li SL, Zhang H, Wang Y, Zhao ZL, Chen SL, Xu HX. Holistic quality evaluation of commercial white and red ginseng using a UPLCQTOF-MS/MS-based metabolomics approach. J Pharm Biomed Anal 2012; 62: 258-273

65 Lee JI, Ha YW, Choi TW, Kim HJ, Kim SM, Jang HJ, Choi JH, Choi MH, Chung $B C$, Sethi G, Kim SH, Ahn KS, Choi SH, Shim BS. Cellular uptake of ginsenosides in Korean white ginseng and red ginseng and their apoptotic activities in human breast cancer cells. Planta Med 2011; 77: 133-140

$66 \mathrm{Kim}$ SN, Ha YW, Shin H, Son SH, Wu SJ, Kim YS. Simultaneous quantification of 14 ginsenosides in Panax ginseng C.A. Meyer (Korean red ginseng) by HPLC-ELSD and its application to quality control. J Pharm Biomed Anal 2007; 45: 164-170

67 Leung KW, Wong AST. Pharmacology of ginsenosides: a literature review. Chin Med 2010; 5: 20

68 Yun TK, Lee YS, Lee YH, Kim SI, Yun HY. Anticarcinogenic effect of Panax ginseng CA Meyer and identification of active compounds. J Korean Med Sci 2001; 16: 6-18

69 Shibata S. Chemistry and cancer preventing activities of ginseng saponins and some related triterpenoid compounds. J Korean Med Sci 2001; 16: S28-S37

70 Kim WY, Kim JM, Han SB, Lee SK, Kim ND, Park MK, Kim CK, Park JH. Steaming of ginseng at high temperature enhances biological activity. J Nat Prod 2000; 63: 1702-1704

71 Kwon SW, Han SB, Park IH, Kim JM, Park MK, Park JH. Liquid chromatographic determination of less polar ginsenosides in processed ginseng. J Chromatogr A 2001; 921: 335-339

72 Park IH, Kim NY, Han SB, Kim JM, Kwon SW, Kim HJ, Park MK, Park JH. Three new dammarane glycosides from heat processed ginseng. Arch Pharm Res 2002; 25: 428-432

73 Lee SM, Shon HJ, Choi CS, Hung TM, Min BS, Bae KH. Ginsenosides from heat processed ginseng. Chem Pharm Bull 2009; 57: 92-94

74 Park IH, Han SB, Kim JM, Piao L, Kwon SW, Kim NY, Kang TL, Park MK, Park JH. Four new acetylated ginsenosides from processed ginseng (sun ginseng). Arch Pharm Res 2002; 25: 837-841

75 Chan EC, Yap SL, Lau AJ, Leow PC, Toh DF, Koh HL. Ultra-performance liquid chromatography/time-of-flight mass spectrometry based metabolomics of raw and steamed Panax notoginseng. Rapid Commun Mass Spectrom 2007; 21: 519-528

76 Toh DF, New LS, Koh HL, Chan EC. Ultra-high performance liquid chromatography/time-of-flight mass spectrometry (UHPLC/TOFMS) for time-dependent profiling of raw and steamed Panax notoginseng. J Pharm Biomed Anal 2010; 52: 43-50

77 Li SL, Song JZ, Qiao CF, Zhou Y, Qian K, Lee KH, Xu HX. A novel strategy to rapidly explore potential chemical markers for the discrimination between raw and processed Radix Rehmanniae by UHPLC-TOFMS with multivariate statistical analysis. J Pharm Biomed Anal 2010; 51: 812823

78 Guo N, Fan B, Peng J, Yan H, Ma F, Yu Y. Ultra-performance LC/TOF MS analysis of fruits of Ligustrum lucidum for metabolomic research. Chin J Exp Tradit Med F 2010; 10: 131-133
79 Wang XJ. Based on NMR/UPLC plant metabonomics study on quality control of Polygala tenuifolia Willd [dissertation]. Shanxi: Shanxi University; 2012

80 Ruan GH, Li GK. The study on the chromatographic fingerprint of Fructus xanthii by microwave assisted extraction coupled with GC-MS. J Chromatogr B Analyt Technol Biomed Life Sci 2007; 850: 241-248

$81 \mathrm{Ni} \mathrm{Y}$, Peng Y, Kokot S. Fingerprinting of complex mixtures with the use of high performance liquid chromatography, inductively coupled plasma atomic emission spectroscopy and chemometrics. Anal Chim Acta 2008; 616: 19-27

82 Tanaka K, Tamura T, Fukuda S, Batkhuu J, Sanchir C, Komatsu K. Quality evaluation of Astragali Radix using a multivariate statistical approach. Phytochemistry 2008; 69: 2081-2087

83 Okada T, Afendi FM, Altaf-Ul-Amin M, Takahashi H, Nakamura K, Kanaya $S$. Metabolomics of medicinal plants: the importance of multivariate analysis of analytical chemistry data. Curr Comput Aided Drug Des 2010; 6: 179-196

84 Tang JC, Zhang JN, Wu YT, Li ZX. Effect of the water extract and ethanol extract from traditional Chinese medicines Angelica sinensis (Oliv.) Diels, Ligusticum chuanxiong Hort. and Rheum palmatum L. on rat liver cytochrome P450 activity. Phytother Res 2006; 20: 1046-1051

85 Li HB, Jiang Y, Wong CC, Cheng KW, Chen F. Evaluation of two methods for the extraction of antioxidants from medicinal plants. Anal Bioanal Chem 2007; 388: 483-488

86 Martin J, Stöger EA, Wiebrecht A. Praxisleitfaden TCM-Drogen-Vorbehandlung-Zubereitung-Sondervorschriften. Dtsch Zeitschrift Akupunktur (DZA) 2009; 52: 72-74

87 Ding Y, Wu EQ Liang C, Chen J, Tran MN, Hong CH, Jang Y, Park KL, Bae K, Kim YH, Kang JS. Discrimination of cinnamon bark and cinnamon twig samples sourced from various countries using HPLC-based fingerprint analysis. Food Chem 2011; 127: 755-760

$88 \mathrm{Ni}$ Y, Zhang L, Churchill J, Kokot S. Application of high performance liquid chromatography for the profiling of complex chemical mixtures with the aid of chemometrics. Talanta 2007; 72: 1533-1539

89 Li Y, Wu T, Zhu J, Wan L, Yu Q Li X, Cheng Z, Guo C. Combinative method using HPLC fingerprint and quantitative analyses for quality consistency evaluation of an herbal medicinal preparation produced by different manufacturers. Pharm Biomed Anal 2010; 52: 597-602

90 Peng JB, Jia HM, Liu YT, Zhang HW, Dong S, Zou ZM. Qualitative and quantitative characterization of chemical constituents in Xin-Ke-Shu preparations by liquid chromatography coupled with a LTQ Orbitrap mass spectrometer. J Pharm Biomed Anal 2011; 55: 984-995

91 Yang CF. Application of UPLC/RRLC/UFLC in study on Chinese materia medica and its preparation. Chin Tradit Herb Drugs 2009; 39: 12591263

92 Zhang $L J$. The development of NMR. J Hebei Morm Univ 2000; 24: 224 227

93 Daolio C, Beltrame FL, Ferreira AG, Cass QB, Cortez DA, Ferreira MM. Classification of commercial Catuaba samples by NMR, HPLC and chemometrics. Phytochem Anal 2008; 19: 218-228

94 Lin Y, Schiavo S, Orjala J, Vouros P, Kautz R. Microscale LC-MS-NMR platform applied to the identification of active cyanobacterial metabolites. Anal Chem 2008; 80: 8045-8054

95 Ali K, Iqbal M, Korthout HA, Maltese F, Fortes AM, Pais MS, Verpoorte R, Choi YH. NMR spectroscopy and chemometrics as a tool for anti-TNFalpha activity screening in crude extracts of grapes and other berries. Metabolomics 2012; 8: 1148-1161

96 Yang J, Xu G, Kong H, Zheng Y, Pang T, Yang Q. Artificial neural network classification based on high-performance liquid chromatography of urinary and serum nucleosides for the clinical diagnosis of cancer. J Chromatogr B Analyt Technol Biomed Life Sci 2002; 780: 27-33

97 Yang $J$, Xu G, Zheng Y, Kong H, Pang T, Lv S, Yang $O$. Diagnosis of liver cancer using HPLC-based metabonomics avoiding false-positive result from hepatitis and hepatocirrhosis diseases. J Chromatogr B Analyt Technol Biomed Life Sci 2004; 813: 59-65

98 Yang J, Xu G, Zheng Y, Kong H, Wang C, Zhao X, Pang T. Strategy for metabonomics research based on high-performance liquid chromatography and liquid chromatography coupled with tandem mass spectrometry. J Chromatogr A 2005; 1084: 214-221

99 Pham-Tuan H, Kaskavelis L, Daykin CA, Janssen HG. Method development in high-performance liquid chromatography for high-throughput profiling and metabonomic studies of biofluid samples. J Chromatogr B Analyt Technol Biomed Life Sci 2003; 789: 283-301 
100 Lenz EM, Wilson ID. Analytical strategies in metabonomics. J Proteome Res 2007; 6: 443-458

101 Chace DH, Kalas TA. A biochemical perspective on the use of tandem mass spectrometry for newborn screening and clinical testing. Clin Biochem 2005; 38: 296-309

102 Fan TW, Lorkiewicz PK, Sellers K, Moseley HN, Higashi RM, Lane AN. Stable isotope-resolved metabolomics and applications for drug development. Pharmacol Ther 2012; 133: 366-391

103 Gad HA, El-Ahmady SH, Abou-Shoer MI, Al-Azizi MM. Application of chemometrics in authentication of herbal medicines: a review. Phytochem Anal 2013; 24: 1-24

104 Dharmaraj S, Jamaludin AS, Razak HM, Valliappan R, Ahmad NA, Harn $G L$, Ismail $Z$. The classification of Phyllanthus niruri Linn. according to location by infrared spectroscopy. Vib Spectrosc 2006; 41: 68-72

105 Vlachos N, Skopelitis Y, Psaroudaki M, Konstantinidou V, Chatzilazarou A, Tegou E. Applications of Fourier transform-infrared spectroscopy to edible oils. Anal Chim Acta 2006; 573-574: 459-465

106 Kokalj M, Kolar J, Trafela T, Kreft S. Differences among Epilobium and Hypericum species revealed by four IR spectroscopy modes: transmission, $\mathrm{KBr}$ tablet, diffuse reflectance and ATR. Phytochem Anal 2011; 22: $541-546$

107 Debonneville C, Thome MA, Chaintreau A. Hyphenation of quadrupole MS to GC and comprehensive two-dimensional GC for the analysis of suspected allergens: review and improvement. J Chromatogr Sci 2004; 42: 450-455

108 Ronda F, Rodríguez-Nogales JM, Sancho D. Multivariate optimisation of a capillary electrophoretic method for the separation of glutenins. Application to quantitative analysis of the endosperm storage proteins in wheat. Food Chem 2008; 108: 287-296

109 Ou LJ, Sun XP, Liu QD, Mi SQ Wang NS. Effects of Rhizoma Zingiberis and Pericarpium Citri reticulatae extracts on myocardial ischemia in rats. Zhong Yao Cai 2009; 32: 1723-1726

110 Ooi LS, Li Y, Kam SL, Wang H, Wong EY, Ooi VE. Antimicrobial activities of cinnamon oil and cinnamaldehyde from the Chinese medicinal herb Cinnamomum cassia Blume. Am J Chin Med 2006; 34: 511-522

111 de Sousa DP, Nobrega FF, de Lima MR, de Almeida RN. Pharmacological activity of (R)-(+)-pulegone, a chemical constituent of essential oils. Z Naturforsch C 2011; 66: 353-359

112 Zhang GC, Fang SM. Antioxidation of Pueraria lobata ilsoflavones. Zhong Yao Cai 1997; 26: 340-343

113 Qi CF, Song SW, Liu DF, Du XF, Wan XC, Song LH. Effects of total isoflavones of Pueraria DC. on bone mineral density and Ca in ovariectomized rats. J Biol 2007; 24: 22-24

114 Gao D, Li Q, Li Y, Liu Z, Fan Y, Zhao H, Li J, Han Z. Antidiabetic and antioxidant effects of oleanolic acid from Ligustrum lucidum Ait in alloxan-induced diabetic rats. Phytother Res 2009; 23: 1257-1262 